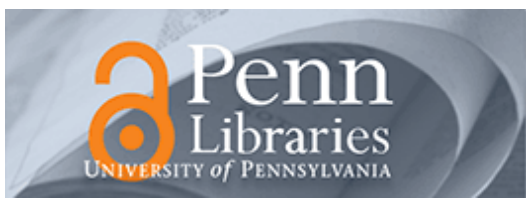

University of Pennsylvania ScholarlyCommons

Department of Medical Ethics and Health Policy

Perelman School of Medicine

$1-1-2011$

\title{
Retirement Effects on Health in Europe
}

Norma B Coe

University of Pennsylvania, nbcoe@pennmedicine.upenn.edu

Gema Zamarro

Follow this and additional works at: https://repository.upenn.edu/mehp

\section{Recommended Citation}

Coe, Norma B and Zamarro, Gema, "Retirement Effects on Health in Europe" (2011). Department of Medical Ethics and Health Policy. 10.

https://repository.upenn.edu/mehp/10

This paper is posted at ScholarlyCommons. https://repository.upenn.edu/mehp/10

For more information, please contact repository@pobox.upenn.edu. 


\title{
Retirement Effects on Health in Europe
}

\begin{abstract}
What are the health impacts of retirement? As talk of raising retirement ages in pensions and social security schemes continues around the world, it is important to know both the costs and benefits for the individual, as well as the governments' budgets. In this paper we use the Survey of Health, Ageing and Retirement in Europe (SHARE) dataset to address this question in a multi-country setting. We use country-specific early and full retirement ages as instruments for retirement behavior. These statutory retirement ages clearly induce retirement, but are not related to an individual's health. Exploiting the discontinuities in retirement behavior across countries, we find significant evidence that retirement has a health-preserving effect on overall general health. Our estimates indicate that retirement leads to a 35 percent decrease in the probability of reporting to be in fair, bad, or very bad health, and an almost one standard deviation improvement in the health index. While the self-reported health seems to be a temporary impact, the health index indicates there are longlasting health differences.
\end{abstract}

\section{Keywords}

Aged, Cross-Sectional Studies, Empirical Research, Europe, Health Status, Health Surveys, Humans, Middle Aged, Retirement 
Published in final edited form as:

J Health Econ. 2011 January ; 30(1): 77-86. doi:10.1016/j.jhealeco.2010.11.002.

\title{
Retirement effects on health in Europe
}

\author{
Norma B. Coe ${ }^{\mathrm{a},{ }^{*}}$ and Gema Zamarro ${ }^{\mathrm{b}}$ \\ aBoston College \& Netspar, United States \\ ${ }^{b}$ RAND Corporation, United States
}

\section{Abstract}

What are the health impacts of retirement? As talk of raising retirement ages in pensions and social security schemes continues around the world, it is important to know both the costs and benefits for the individual, as well as the governments' budgets. In this paper we use the Survey of Health, Ageing and Retirement in Europe (SHARE) dataset to address this question in a multicountry setting. We use country-specific early and full retirement ages as instruments for retirement behavior. These statutory retirement ages clearly induce retirement, but are not related to an individual's health. Exploiting the discontinuities in retirement behavior across countries, we find significant evidence that retirement has a health-preserving effect on overall general health. Our estimates indicate that retirement leads to a 35 percent decrease in the probability of reporting to be in fair, bad, or very bad health, and an almost one standard deviation improvement in the health index. While the self-reported health seems to be a temporary impact, the health index indicates there are long-lasting health differences.

\section{Keywords}

Health; Retirement; Mental health

\section{Introduction}

The notion that retirement harms health is an old and persistent hypothesis (see Minkler, 1981, for a review). Many argue that retirement itself is a stressful event (Carp, 1967; Eisdorfer and Wilkie, 1977; MacBride, 1976; Sheppard, 1976). Retirement can also lead to a break with support networks and friends, and may be accompanied by emotional or mental impacts of "loneliness," "obsolesce," or "feeling old" (Bradford, 1979; MacBride, 1976). Others believe that retirement is a health-preserving life change. Anecdotal evidence suggests that many discussions about the retirement decision include the idea that work is taxing to the individual, thus retirement would remove this stress and preserve the health of the retiree (Ekerdt et al., 1983).

Despite the long-standing debate, there is little conclusive empirical evidence thus far. The inherent problem is that retirement is often a choice, and is often based on health characteristics before retirement. Many of the early studies do not address this, thus they can only infer correlation, not causality. Compounding the problem is that some of the studies find a positive correlation with health (Thompson and Streib, 1958), no correlation with health (Carp, 1967; Atchley, 1976; Kasl, 1980; Rowland, 1977; Haynes et al., 1978; Niemi,

(C) 2010 Elsevier B.V. All rights reserved.

"Corresponding author at: Center for Retirement Research at Boston College, Hovey House, 140 Commonwealth Avenue, Chestnut Hill, MA 02467, United States. Tel.: +1 617552 1762; fax: +1 617552 0191. Norma.Coe@bc.edu (N.B. Coe). 
1980; Adams and Lefebvre, 1981), or a negative correlation with health (Casscells et al., 1980; Gonzales, 1980).

A few recent papers try to address the endogeneity of the retirement decision in examining future health. Charles (2004) and Neuman (2008) use age-specific retirement incentives provided by the U.S. Social Security regulations as instrumental variables in the U.S. context. Coe and Lindeboom (2008) also use early retirement window offers as an instrument. The results from these papers combined indicate that retirement has a positive effect on subjective measures of health, but no effect on objective measures of health in the United States. There is no a priori reason to assume that findings from the U.S. situation will hold for European countries, considering the numerous differences in the labor markets, health insurance, and social policies.

Kerkhofs and Lindeboom (1997) assess the effects of work history on the health status of older Dutch workers using fixed effects regressions. This accounts for time-invariant factors that may confound the results, but it does not control for time-varying factors such as a sudden change in the individual environment. Their results suggest that health deteriorates with increased work effort and that increasing retirement ages may negatively influence later-life health outcomes. Lindeboom et al. (2002) use a fixed effect control function to assess the effect of life events, such as retirement, on the mental health of older individuals, also in the Dutch setting. They try to control for all transitory changes as well as individual fixed effects. They find no statistical effect of loss of work on mental health two years later. Their approach does not address any physical health effects of retirement. In fact, they control for all physical health deterioration that is observed in the data. Thus, this result may fail to measure the total impact of retirement on overall health.

Bound and Waidmann (2007) examine the health effects of retirement in the U.K. using one wave of the English Longitudinal Study of Aging (ELSA). They examine both self-reported measures of health and objective measures of health measured through blood samples. They find some evidence of a positive health effect of retirement, although temporarily, for men, and no corresponding relationship for women.

Three recent papers examine the relationship between cognitive functioning and retirement. Adam et al. (2006) find a strong association between cognitive decline and retirement, but do not test for causality. Coe et al. (2009) find no causal relationship between cognitive function and retirement in the United States, while Rohwedder and Willis (2010) use crosscountry variation in retirement ages and find a strong relationship between retirement and cognitive decline.

We examine the effect retirement has on contemporaneous health and cognitive function in a multi-country setting using within-country variation in retirement behavior using the SHARE dataset. In addition to demographic information, the survey collects detailed information concerning retirement behavior. The health information is rich, and includes self-reported health, diagnoses of diseases, the Euro-D depression index, as well as newer, more powerful predictors of mortality, such as grip strength. We have supplemented the data with information on early and full statutory retirement ages in 11 countries.

We use a single cross-section of data from multiple countries and use the differing retirement ages across countries as exogenous instruments for the retirement decision. Unlike single-country analysis, we can exploit the exogenous variation in retirement policies to explore the effect of retirement on health at different ages, not just age 65, as in the U.K. and U.S. studies. To our knowledge, no other paper in the literature has examined if there are different relationships between retirement and health based on age of retirement. 
The paper proceeds as follows. Section 2 discusses the empirical model, while the data and the definition of key variables are introduced in Section 3. In Section 4 we present the results and conclude in Section 5.

\section{Empirical approach}

\subsection{Design}

We aim to determine the effect of the binary decision of being retired $\left(D_{i}=1\right)$ on a measure of health $\left(Y_{i}\right)$ (i.e., general health measures, cognitive ability, or depression measures). The traditional approach consists of estimating the following equation by OLS:

$$
Y_{i}=\alpha+\beta D_{i}+u_{i} \quad(1)
$$

However, a selection problem may arise; namely, $D_{i}$ can be correlated with the unobservables $u_{i}$. This could happen if people self-select into retirement earlier based on their gains to being retired, e.g., those who enjoy their jobs the least retire early to be happier or those with the most physically demanding jobs retire earlier to relieve themselves of the daily strain. If this is the case, OLS estimates of $\beta$ are not consistent.

The instrumental variables approach we use solves the problem by exploiting the fact that the regressor of interest (retirement) is partially determined by a known, discontinuous function that is not related to individual health $\left(Y_{i}\right)$. The rules determining the eligibility ages for early and full retirement dramatically change the probability of retiring discontinuously as a function of age and the country in which one lives. Thus we can use these age thresholds as instrumental variables to identify the causal relationship between retirement and health. Although retirement and the instruments used are both a function of age themselves, this function is nonlinear and non-monotonic. We can therefore control for a wide range of smooth age effects in health when using early and full retirement ages as instruments. ${ }^{1}$

Let $S_{i}$ be the age of the individual and $S$ the early or full retirement age in that country. The identification strategy exploits the fact that while being above the age threshold does not perfectly determine retirement behavior, it does create a discontinuity in its probability. Using a two-step estimation procedure, we first estimate:

$$
E\left(D_{i} \mid S_{i}\right)=f\left(S_{i}\right)+\gamma I\left(S_{i} \geq \bar{S}\right)
$$

where $f\left(S_{i}\right)$ is a general and continuous function of $S$ and $I\left(S_{i} \geq S\right)$ is an indicator function for being over the eligibility ages for early and full retirement. $\gamma$ measures the discontinuity in the propensity score function at $S$. We use the predicted values from the first stage in order to estimate:

$$
Y_{i}=\alpha+\beta E\left(\widehat{D_{i} \mid S_{i}}\right)+\gamma K\left(S_{i}\right)+w_{i}
$$

where $K\left(S_{i}\right)$ is a general control function. In this paper, we limit the cases we consider to parametric estimation, assuming the same functional form for $K\left(S_{i}\right)$ and $f\left(S_{i}\right)$. This assumption means that this two-stage procedure is equivalent as two-stage least squares, where being over the eligibility ages for early and full retirement are used as instruments.

\footnotetext{
${ }^{1}$ This approach can also be seen as an application of regression discontinuity design, as was done in Campbell (1969), Angrist and Lavy (1999), and Van der Klaauw (2003), among others.
} 
IV estimation hinges on the assumptions that the instruments are relevant and that there are no other discrete changes to individual health that coincide with the retirement age. Previous literature has shown the relevance of the rules determining Social Security benefits on determining the timing of retirement (see Hurd, 1990, and Lumsdaine and Mitchell, 1999, for reviews; Zissimopoulos et al., 2007; Poterba et al., 2004; Anderson et al., 1999; Samwick, 1998). Likewise, other cross-national research, for example, Gruber and Wise (1999), Gruber and Wise (2004), notes that there is a strong negative correlation between labor force participation at older ages and the generosity of early retirement benefits. In addition, the most recent strand of the retirement and health literature (see Charles, 2004; Neuman, 2008; Bound and Waidmann, 2007; Coe and Lindeboom, 2008; Rohwedder and Willis, 2010) has illustrated that using institutional variation in retirement incentives is a valid identification technique. Although not directly testable, we believe that it is appropriate to assume that there are no other discrete changes to individual health that coincide with the retirement ages. In contrast to the U.S. Medicare program, European health benefits are not contingent on being a specific age, and we are not aware of any other possible causes to produce changes in health at the exact retirement ages set in each country. Finally, since we have an overidentified model, we present Sargan test statistics for the overall validity of the instruments.

It should be stressed that by estimating equation (3) we are attempting to measure a contemporaneous effect of retirement on health, and not a cumulative one. Substantial changes in one's life, such as shocks to one's employment or daily schedule, may have contemporaneous impacts on measures of health and well-being, and it is an empirical question, whether the contemporaneous or the cumulative effect is larger. An alternative specification, used by Bound and Waidmann (2007), looks for shifts that occur after retirement both in the levels of health as well as in the age trends in health. We include robustness checks to examine for changes in the age trends in health in Section 4.4.

\subsection{Heterogeneity}

We are concerned that retirement might have different effects on health for different individuals. For example, retirement from a job that requires strenuous physical labor might affect one's health differently than retiring from a desk job. Due to data limitations, we cannot control for many characteristics of the job an individual retires from, and thus we have limited ability to identify the underlying distribution of health effects. While the individual effects are important for individual decisions, our methodology allows us to identify an average effect of retirement on health, which should be of interest to policymakers setting early and full retirement ages.

More formally, let $Y_{1 i}$ denote the health of an individual when he is retired $\left(D_{i}=1\right)$ and $Y_{0 i}$ his health in the case of not being retired $\left(D_{i}=0\right)$. The evaluation problem arises because people either are retired or not and no individual is observed in both states at the same time. We would like to know what is the effect of retirement on health $\left(Y_{1 i}-Y_{0 i}\right)$, but what we observe is:

$$
Y_{i}=D_{i} Y_{1 i}+\left(1-D_{i}\right) Y_{0 i}
$$

So far we have assumed that the effect is homogeneous among individuals $\left(\left(Y_{1 i}-Y_{0 i}\right)\right.$ is constant $\forall i$ ). If there is a distribution of effects in the population, our estimates should be interpreted as the average effect of retirement at the threshold $S\left(E\left(Y_{1 i}-Y_{0 i} \mid S_{i}=S\right)\right)^{-}{ }^{2}$ That

\footnotetext{
${ }^{2}$ See Hahn et al. (2001).
} 
is, we measure the average health effects across individuals induced by the incentives built into pension systems to retire at the early or normal retirement age set in their country. Country-level fixed-effects will pick up any systematic differences in other labor force exit routes that exist between countries (such as generous disability insurance programs).

\section{Data}

For this paper we use wave 1, release 2 of the Survey of Health, Ageing and Retirement in Europe (SHARE) ${ }^{3}$. SHARE is a multidisciplinary, cross-national, individual-level dataset on health, socioeconomic status, and social and family networks. SHARE is unique in three important ways: it is multidisciplinary, cross-country comparable, and eventually longitudinal. The data we use is the first wave of the survey, 2004, containing information on approximately 31,000 individuals over age 50, in the following countries: Austria, Germany, Sweden, the Netherlands, Spain, Italy, France, Denmark, Greece, Switzerland, and Belgium. ${ }^{4}$ In addition to demographic information, there is also a wealth of socioeconomic variables (including labor situation, wealth, consumption and housing) and detailed health status information, including self-reported health, diagnoses of diseases, the Euro-D depression index, as well as newer, more powerful predictors of mortality, such as grip strength and walking speed.

There are very few sample restrictions necessary for this analysis. First, we eliminate incomplete survey records. Second, we keep those individuals who are between 50 and 69 years old. We eliminate those individuals who have never worked and those who have not worked since age 50, either due to individual choice or physical or mental limitations. Finally, we limit our analysis to men, since we are less worried about the potential for cohort effects in the characteristics of the working population for men than for women. Otherwise, this dataset is perfectly suited to our needs, sampling near- and post-retirement-age individuals in a variety of institutional settings. The final sample consists of $5282 \mathrm{men}$.

We supplemented this dataset with the early and full retirement ages in place in each country in 2004 (see Table 1). ${ }^{5}$ Retirement ages vary by country and sometimes by gender, by as much as eight years. The earliest age for retirement is 57, and the latest is age 65 .

\subsection{Measuring health}

3.1.1. Self-reported health and health index-Health is a difficult concept to measure in survey data. Objective measures of health often only ask about specific diseases, and thus are incomplete. Self-reported general health questions may provide a more complete picture of one's overall well-being, and consistently are found to be a significant predictor of mortality, even after one controls for many more objective measures of health. In SHARE,

\footnotetext{
${ }^{3}$ For more information about SHARE, see http://www.share-project.org/. This paper uses data from release 2.0.1 of SHARE 2004. The SHARE data collection has been primarily funded by the European Commission through the 5th framework programme (project QLK6-CT-2001-00360 in the thematic programme Quality of Life). Additional funding came from the U.S. National Institute on Aging (U01 AG09740-13S2, P01 AG005842, P01 AG08291, P30 AG12815, Y1-AG-4553-01 and OGHA 04-064). Data collection for wave 1 was nationally funded in Austria (through the Austrian Science Foundation, FWF), Belgium (through the Belgian Science Policy Office), France (through CNAM, CNAV, COR, Drees, Dares, and Caisse des Dépôts et Consignations et le Commissariat Général du Plan) and Switzerland (through BBW/OFES/UFES). The SHARE data collection in Israel was funded by the U.S. National Institute on Aging (R21 AG025169), by the German-Israeli Foundation for Scientific Research and Development (G.I.F.), and by the National Insurance Institute of Israel. Further support by the European Commission through the 6th framework program (projects SHARE-I3, RII-CT-2006-062193, and COMPARE, CIT5-CT-2005-028857) is gratefully acknowledged. For methodological details see Börsch-Supan and Jürges (2005).

${ }_{5}^{4}$ SHARE data also collects information in Israel that was not considered in our analysis.

5 The main source for this data was Natali (2004), but was supplemented with information from OECD (2003), the Bartelsmann Foundation, Sundén (2004), Preesman (2006), and OECD (2005). Slight differences can be found between our retirement ages and those from other OECD publications (for example, OECD, 2005), due to the differences between current law and the law that was in place when these individuals were facing the retirement decision.
} 
respondents are asked to rate their health on a five-point scale: very good, good, fair, bad and very bad. ${ }^{6}$ We then condense these responses to a two-point scale: bad health (poor, bad, or very bad) and good health (good and very good).

Self-reported health may have other problems, though. It may suffer from justification bias, and thus may be endogenous to retirement behavior. There is a large literature discussing how to create a reliable, meaningful measure of health, but it varies widely conceptually and methodologically. One alternative that combines both the subjective and objective measures of health in one comprehensive measure is to create a health index, first introduced in Bound et al. (1999).

As in Bound et al. (1999), we predict self-reported health using all available objective measures of health. The created "health stock" variable will allow us to aggregate a variety of measures of health into one, while ameliorating the reporting bias in the self-reported health variable. ${ }^{7}$ In particular, we create a health index by estimating:

$$
H_{i}=\alpha+\beta L_{i}+\mu_{i}
$$

where $H_{i}$ is self-reported health, ranging on a five-point scale from very good (1) to very bad (5) health. $L$ includes individual objective measures of health. In this respect, the SHARE dataset has extensive health measures. We include variables measuring limitations to activities due to health reasons, the number of limitations in activities of daily living (ADLs), ${ }^{8}$ the number of limitations in the instrumental activities of daily living (IADLs), ${ }^{9}$ the number of chronic diseases, ${ }^{10}$ the number of limitations with mobility, including arm function and fine motor function, ${ }^{11}$ grip strength, indicators for overweight and obesity as measured by body mass index (BMI), a depression index as measured by the Euro-D scale, 12 number of chronic symptoms, ${ }^{13}$ physical inactivity, and hospitalizations within the last year.

Different countries may have different "norms" in reporting self-assessed measures of health (Kapteyn et al., 2008). Thus we alter the Bound approach slightly, estimating equation (4) separately for each of the 11 countries in our sample. This controls for different means and different cut-points in self-reported health across countries. Table 2 shows the ordered probit results. A positive coefficient indicates that the condition leads to reporting of worse health. The coefficients are intuitively consistent; more health problems lead to lower reported health. Reporting limitations with activities and the number of chronic illnesses are consistently significant regressors for self-reported health. Interestingly, despite the concern about different reporting standards used across countries, in most cases, the estimates for the

\footnotetext{
${ }^{6}$ A second version of the five-point scale (excellent, very good, good, fair, and poor) is also recorded to be comparable to the Health and Retirement Study. We do not use this second version in the paper.

${ }^{7}$ Bound et al. (1999) also use changes in the health stock, or "health shocks," to predict retirement behavior, but as of now, we do not have a long panel dataset for SHARE.

${ }^{8}$ ADLs measure limitations in the following skills: bathing, dressing, toilet use, transferring (in and out of a bed or chair), urine and bowel continence, and eating.

9IADLs measure the following skills: use of the telephone; traveling via car or public transportation; food or clothes shopping; meal preparation; housework; medication use (preparing and taking correct dose); management of money (writing checks, paying bills).

10 The number of chronic diseases is a count of the following diseases an individual might have: heart problems; high blood pressure; high cholesterol; cerebral vascular disease; diabetes; lung diseases; asthma; arthritis; osteoporosis; cancer; stomach ulcer; Parkinson's disease; cataracts; hip fracture or femoral fracture.

${ }^{11}$ The mobility measure includes information on the ability to walk $100 \mathrm{~m}$, the ability to sit in a chair for $2 \mathrm{~h}$ or more, and the ability to get up from a chair unaided after sitting.

${ }^{12}$ The Euro-D scale runs from 0 to 12, measuring the number of depression symptoms including: depression; pessimism; suicidality; guilt; sleep; lack of interest; irritability; appetite; fatigue; concentration; enjoyment; and tearfulness.

${ }^{13}$ The number of chronic symptoms is a count variable for individuals reporting any of the following conditions in the previous six months: pain in the back, knees, hips or any other joint; heart trouble; breathlessness; persistent cough; swollen legs; sleeping problems.
} 
marginal effect of the various health conditions on self-reported health are not statistically different among countries. The last row in Table 2 presents the average predicted health index value for each country. Sweden and Italy appear the healthiest, while Denmark and Switzerland have the most health impairments on average.

3.1.2. Depression-We use two measures of depression in this analysis. The first is the Euro-D depression scale. Unlike the measurement of health, the depression scale was specifically developed for detecting depression and has been validated for use in crosscountry analysis (see Larraga et al., 2006; Price, 2002). The Euro-D scale runs from 0 to 12, counting whether the individual reported having problems with the following feelings in the prior month: sadness or depression; pessimism; suicidal thoughts; guilt; sleep trouble; lack of interest; concentration; appetite; irritability; fatigue; enjoyment; and tearfulness. We also use a simple indicator variable for whether or not the individual reports being sad or depressed in the previous month.

3.1.3. Cognitive ability-The cognitive reserve is defined in the neuro-psychological literature as the individuals' capacity to use brain networks more efficiently or, in other words, to process tasks in a more efficient manner (Stern, 2002). The decline in cognitive function with age is associated with structural changes in the brain (Raz, 2004). In addition, this cognitive decline is associated with diseases such as Alzheimer's.

Adam et al. (2006), using SHARE data, found that occupational activities, including paid work and non-paid work as well as sport practice and other physical activities, are highly correlated with cognitive ability. However, they cannot address whether this is due to a causal link between paid work and cognitive ability.

In SHARE, cognitive ability is measured through several questions. Memory is tested through word recall. The respondents are asked to memorize a list of 10 common words. They are then asked to recall these words two times, once immediately and once again after a considerable delay spent answering more survey questions. The memory scale ranges from 0 to 20 , with 20 being the highest. Verbal fluency is assessed by asking respondents to name as many animals as possible within a 1-min time frame. This variable ranges between 0 and 72 .

Following Adam et al. (2006), we estimate the effect of retirement on memory and verbal fluency scores, but correct for the endogeneity in retirement using our early and full retirement ages as instrumental variables. For this analysis, we limit the sample further by dropping those individuals who had suffered a vascular accident, have Parkinson's disease, had brain cancer, are taking medicine for depression, and those who have ever been hospitalized in a psychiatric institution. Thus our sample size drops to 4928.

\subsection{Retirement definition}

There are two common ways of defining retirement: self-reported retirement status, or anyone who is not in the paid labor force. Often individuals report that they are retired even when working full- or part-time, simply because they have left their "career" job. Since we want to determine the effect of work status on health, we employ the latter definition. We consider this a cleaner measure of retirement behavior than the self-reported measure. Thus, while we limit our sample to those who are working in the paid labor market at age 50, we consider individuals who report themselves to be retired, a homemaker, sick and disabled, separated from the labor force (not temporarily), and unemployed (not temporarily) as retired. 


\subsection{Instruments}

We use early and full statutory retirement ages in each country's social security scheme as instrumental variables (see Table 1). There is an eight-year difference in the ability to collect early retirement benefits in our sample, from age 57 in Italy to age 65 in Denmark (where there is no early retirement). These are highly significant in predicting retirement behavior, but since these are national eligibility ages, there is no reason to think they are linked to any particular individual's health. Further, it is difficult to imagine that there are breaks in the health trajectory at different ages in different countries. For example, there is no reason to believe that there is an independent, age-specific, nonlinear change in health at age 57 for Italian men, age 60 for Belgian men, and age 65 for Danish men.

There are, certainly, different ways to exit the labor force, such as through unemployment or disability programs. To the extent that these patterns are stable within countries, the country fixed-effect will pick up this variation, and it will not bias our results. By using the statutory retirement ages as instruments, we are measuring the impact of retirement on health for those whose decision to retire is a function of these ages.

\subsection{Descriptive statistics}

Table 3 provides the descriptive statistics for the full sample. The average age of the sample is 59 years, with 24 percent being over the full retirement age and an additional 46 percent over the early retirement age of their country. Eighty-one percent are still married or coreside. While only 25 percent report being in fair, bad, or very bad health, we do see a number of health limitations. Twenty-eight percent report that health has limited their activities in the previous six months. The more severe measures of health decline, such as the number of ADLs, IADLs, or mobility limitations, are still, on average, quite low. While the average Euro-D depression measure is also low (only 1.6 out of 12), 26 percent of our sample reported feeling depressed in the previous month. We also find that half of our sample is overweight, while another 17 percent is obese (as measured by BMI greater than 24). On average, our sample can recall just under 22 animals in $1 \mathrm{~min}$, and can recall just under 10 words when asked to do so both immediately and again after some time has elapsed.

Forty-five percent of our sample is out of the labor market. We also control for sector of employment in our regressions, where 18 percent are self-employed and another 12 percent work for the public sector. One can also see the country-by-country breakdown of our sample. The most respondents come from Belgium, Germany, Sweden, the Netherlands, and France. Switzerland is the country with the fewest respondents.

\section{Results}

\subsection{Instrument validity}

In order for statutory retirement ages to be valid instruments, they must be related to actual retirement behavior. Said differently, the propensity to retire must change at these given ages. Ideally, we would illustrate this point with country-specific retirement hazard rates. Since we do not have panel data, we instead report the fraction of individuals retired before they are eligible for social security, when they are between the early and normal retirement ages and after the normal retirement age in Table 1. There is a dramatic increase in the fraction of the sample retired at both the early cut off and the normal retirement age cutoff in every country. For example, only 20 percent of the sample in Austria is out of the labor market before they are eligible for the state pension. This fraction increases to 86 percent for those who are between the early retirement eligibility age and the normal retirement age. Virtually all of those over the full retirement age, 97 percent, are out of labor market. 
The first stage regression indicates that early and full retirement ages are important predictors for retirement behavior. Table 4 presents the coefficients of estimating equation (2) for Europe. This indicates that being over the early retirement age increases the probability of being out of the labor force by 0.08 points, while being over the full retirement age increases the probability by almost 0.15 points. Once controlling for these country-specific age breaks, age itself is not statistically important for retirement behavior. The coefficients on the rest of the variables are as one would expect: self-employed and public-employed individuals are less likely to retire, and the more education one has, the less likely they are to retire. The country control variables are also quite significant.

\subsection{Self-reported health, depression, and cognitive ability}

Table 5 presents the baseline results for Europe. The table presents the results for selfreported health (columns 1 and 2), the health index (columns 3 and 4), and the two measures of depression (columns 5-8). The first column of each pair presents the OLS results, which ignores the endogeneity of retirement and health, while the second column presents our preferred IV estimates.

Most of the effects of the control variables are statistically significant and as we would intuitively expect. Higher education tends to be associated with better health, and marriage is correlated with lower incidence of depression. Many of the country indicator variables are significant. A few surprises do occur. The more children one has, the worse health they are in and the more likely they are to report depression. We interpret this result as a socioeconomic status or wealth indication, not that children themselves are bad for one's health. Age has surprisingly little effect on any of our health measures, and we find no evidence of a nonlinear relationship once we control for retirement behavior. We also added controls for the season of interview for the depression regressions and find that these are insignificant.

The OLS results indicate that retirement is associated with a 14 percent increase in the likelihood of reporting in fair, bad, or very bad health. Once we take into account the endogeneity of health and retirement, we find that retirement induced by social security leads to a 0.35 point decrease in the probability of reporting in fair, bad, or very bad health. We find similar results when we use the health index instead of the self-reported health measure. Remember, the health index is a way to aggregate multiple measures of health (both objective and subjective). Here we find that there is a positive coefficient in the OLS, indicating a negative correlation between retirement and health, similar to the self-reported health findings. Again, once taking into account the endogeneity of the retirement decision, the sign reverses and we find that retirement leads to almost a one standard deviation decrease in the health index (indicating better health).

For both measures of depression, we find that there is a statistically significant and positive correlation between depression and retirement. However, we find no evidence of a causal mechanism, since our IV coefficients are statistically insignificant. As mentioned above, the sample for testing the effect of retirement on cognitive function is slightly smaller due to sample limitations. In addition to the control variables we included above, we also add a dummy for the individual being born out of the country, number of ADLs, number of IADLs, number of chronic diseases, number of non-professional activities done, a dummy for doing physical demanding activities (sports, heavy work) and less demanding activities (e.g., gardening) at least once per week in order to make our results directly comparable to Adam et al. (2006).

Much like the previous research, we also find a strong negative correlation between retirement and cognitive function in both the memory and the verbal measures, as can be 
seen in Table 6. However, once we control for the endogeneity of the retirement decision, the coefficients become insignificant, and thus suggest there is no causal relationship between work status and decline of cognitive skills. This is consistent with Coe et al. (2009), who find no causal relationship between retirement and cognitive functioning in the U.S. However, by using intra-country differences to identify this effect, we do not find the negative effect of Rohwedder and Willis (2010).

\subsection{Age gradient of the retirement effect}

By examining the health-retirement relationship in a multi-country setting, we can see whether there are differential health effects of working longer/retiring earlier. Since we have varying ages of retirement, especially early retirement, among countries, we allow for different retirement effects depending on the age when the individuals retired (ages 57-59, ages 60-64, and ages 65-69).

The results are presented in Table 7. We present the OLS results and the IV estimation for self-reported health (columns 1 and 2) and the health index (columns 3 and 4). ${ }^{14}$ Once we control for endogeneity, the coefficient pattern suggests an age-gradient story. For example, people who retire between ages 60-64 when their country allows for retirement are 54 percent less likely to report being in bad health than those who retire before age 57 . However, these results are only suggestive, since the standard errors are rather large, and $t$ tests reject significant differences between the coefficients on the age categories.

\subsection{Robustness checks}

Conditions during the life cycle-One concern is that there might be other things that could cause a nonlinear relationship between health and age other than retirement at these particular ages. Lindeboom et al. (2003) find that macroeconomic events during early life and childhood have an effect on lifetime health, and thus these nonlinearities we find could be due to differences in childhood resources. Given the age of the individuals, the biggest concern is that World War II (or the Spanish Civil War), or famines related to these wars, could be driving the results, leading to one-time differences between these particular cohorts, and not a general effect of retirement on health. We added variables indicating if someone was born between the date of war declaration and peace treaty signing in their particular country. There is no change in the estimated effect of retirement on self-reported health or the health index, and the coefficients on these indicator variables for being born during a war or a famine are insignificant themselves.

Age gradient specification-As discussed above, retirement could impact health contemporaneously, over time, or both. The previous results only examine the contemporaneous effects. However, the specification relies on proper estimation for the age gradient itself. We have tried linear, quadratic (presented), and quartic age terms in robustness checks, all of which lead to virtually identical results. Another technique, used in Bound and Waidmann (2007), is to look directly for breaks in trends along ages that correspond to the early or full retirement ages in specific countries. Instead of the IV method, we rely on OLS regressions and include a full set of indicator variables for: chronological age, being at the early retirement age, the number of years past the early retirement age, being at the full retirement age, and the number of years past the full retirement age. Fig. 1 plots the estimated relationship between age and self-reported bad health using this technique, by groups of countries as defined by their early retirement age, and normalizing the scale, setting age 50 equal to zero. ${ }^{15}$ Denmark, having no early

\footnotetext{
${ }^{14}$ Results for depression and cognitive function are available from the authors, but much like the results presented in Tables 5 and 6 , we find no causal relationship between work status and depression or cognitive function.
} 
retirement age, is the solid line. As each group of countries experiences its early retirement age, there is a marked instant improvement in self-reported health. This furthers the argument that the earlier results are not due to a misspecification of the underlying relationship between age and health.

\section{Conclusion}

We find that there is a statistically significant and economically important effect of retirement on general health. We also illustrate the importance of looking for the causal effect, instead of just raw correlations, between retirement and health status, since we find no evidence of a causal link between work status and depression or cognitive function.

Our estimates indicate that planned retirement induced by government social security systems leads to a 35 percent decrease in the probability of reporting in fair, bad, or very bad health, and an almost one standard deviation improvement in the health index. It is, however, difficult to quantify these results. Self-reported health has been found to be an important predictor for mortality, especially for death due to diabetes, infection, or respiratory diseases. Benjamins et al. (2004) finds that individuals who rate themselves in fair (poor) health are four- (six-) times more likely to die from diabetes than those who report they are in excellent health, respectively. Further research is needed to determine if these health improvements lead to quality-of-life improvements, and how to quantify the relationship between labor market activity and health care expenditures. A full welfare analysis could be useful in order to determine relative gains to those who benefit from early retirement against the costs to society of too early of a retirement of those who could work longer without a health impact.

Next, we would like to explore the underlying mechanisms for how and why health is increasing after retirement. It is important to determine if individuals are using the extra time to make further health investments, and which health investments are being made. This could help direct public policy measures to decrease the effect of working on health, and potentially increasing the retirement age without experiencing the declines in health that are suggested by the results of this paper.

\section{Acknowledgments}

We gratefully acknowledge funding for this project from the Marie Curie International Fellowship (Coe), the Roybal Center for Health Policy Simulation, funded by the National Institute of Aging (5P30 AG024968-02) (Zamarro), and grant number P01 AG022481-01A1 from the National Institute of Aging (Zamarro). We thank Anamaria Camacho for research assistance. We would like to thank Arie Kapteyn, participants of seminars from RAND Corporation, Tilburg University, Michigan Retirement Research Center, the Workshop on the Economics of Aging (Turin), the Netspar Health Workshop (Maastricht), and three anonymous referees for very helpful comments. Any errors are our own.

\section{References}

Adam, S.; Bay, C.; Bonsang, E.; Germain, S.; Perelman, S. CREPP Working Paper 2006/05. 2006. Occupational Activities and Cognitive Reserve: A Frontier Approach Applied to the Survey on Health, Ageing, and Retirement in Europe (SHARE).

Adams O, Lefebvre L. Retirement and mortality. Aging and Work. 1981; 4 (2):115-120. [PubMed: 12312403]

\footnotetext{
${ }^{15}$ Only countries with age 65 full retirement age are included in the figure, full results for bad health, the health index, and cognitive impairment are available upon request.
} 
Anderson, Gustman; Steinmeier. Trends in male labor force participation and retirement: some evidence on the role of pensions and social security in the 1970s and 1980s. Journal of Labor Economics. 1999; 17 (4 part 1):757-783.

Angrist JD, Lavy V. Using maimonides rule to estimate the effect of class size on scholastic achievement. Quarterly Journal of Economics. 1999; 114:533-575.

Atchley, RC. The Sociology of Retirement. Halsted Press; New York: 1976.

Benjamins MR, Hummer RA, Eberstien IW, Nam CB. Self-reported health and adult mortality risk: an analysis of cause-specific mortality. Social Science and Medicine. 2004; 59 (6):1297-1306. [PubMed: 15210100]

Bradford LP. Can you survive your retirement? Harvard Business Review. 1979; 57 (4):103-109.

Börsch-Supan, A.; Jürges, H. The Survey of Health Ageing and Retirement in Europe-Methodology Mannheim Research Institute for the Economics of Aging. University of Mannheim; 2005.

Bound, J.; Waidmann, T. University of Michigan Retirement Research Center working paper 2007-168. 2007. Estimating the Health Effects of Retirement.

Bound J, Schoenbaum M, Stinebrickner T, Waidmann T. The dynamic effects of health on the labor force transitions of older workers. Labour Economics. 1999; 6 (2):179-202.

Campbell D. Reforms and experiments. American Psychologist. 1969; 24:409-429.

Carp FM. Retirement crisis. Science. 1967; 157:102-103. [PubMed: 6026662]

Casscells W, Evans D, DeSilva R, Davies JE, Hennekens CH, Rosner B, Lown B, Jesse MJ. Retirement and coronary mortality. Lancet I. 1980; (8181):1288-1289.

Charles KK. Is retirement depressing? Labor force inactivity and psychological well-being in later life. Research in Labor Economics. 2004; 23:269-299.

Coe, N.; Lindeboom, M. CentER Discussion paper 2008-93. 2008. Does Retirement Kill You? Evidence from Early Retirement Windows.

Coe, N.; von Gaudecker, HM.; Lindeboom, M.; Maurer, J. Netspar Discussion Paper 10/2009-044. 2009. The Effect of Retirement on Cognitive Functioning.

Ekerdt D, Raymond Bosse J, LoCastro JS. Claims that retirement improves health. Journal of Gerontology. 1983; 38:231-236. [PubMed: 6827042]

Eisdorfer, C.; Wilkie, F. Stress, disease aging and behavior. In: Birren, JE.; Shaie, KW., editors. Handbook of the Psychology of Aging. Van Nostrand Reinhold; New York: 1977. p. 251-275.

Gonzales ER. Retiring may predispose to fatal heart attack. Journal of the American Medical Association. 1980; 243:13-14. [PubMed: 7350326]

Gruber, Jonathan; Wise, DA. Social Security and Retirement around the World. University of Chicago Press; Chicago: 1999.

Gruber, Jonathan; Wise, DA. Social Security Programs and Retirement around the World: Microestimation. University of Chicago Press; Chicago: 2004.

Hahn J, Todd P, Van der Klaauw W. Identification and estimation of treatment effects with a regression-discontinuity design. Econometrica. 2001; 69:201-209.

Haynes SG, McMichael AJ, Tyroler HA. Survival after early and normal retirement. Journal of Gerontology. 1978; 33:269-278. [PubMed: 627711]

Hurd MD. Research on the elderly: economic status retirement, and consumption and saving. Journal of Economic Literature. 1990; 28(June 2):565-637.

Kapteyn A, Smith JP, van Soest A. Vignettes and self-reported work disability in the Netherlands and the US. American Economic Review. 2008; 97 (1):461-473.

Kasl, SV. The impact of retirement. In: Cooper, CL.; Payne, R., editors. Current Concerns in Occupational Stress. John Wiley; New York: 1980.

Kerkhofs M, Lindeboom M. Age related health dynamics and changes in labor market status. Health Economics. 1997; 6:407-424. [PubMed: 9285233]

Larraga L, Saz P, Dewey ME, Marcos G, Lobo A. the ZARADEMP Workgroup. Validation of the Spanish version of the Euro-D Scale: an instrument for detecting depression in older people. International Journal of Geriatirc Psychiatry. 2006; 21:1199-1205. 
Lindeboom M, Portrait F, van den Berg GJ. An econometric analysis of the mental-health effects of major events in the life of older individuals. Health Economics. 2002; 11 (6):505-520. [PubMed: 12203754]

Lindeboom, M.; Portrait, F.; van den Berg, GJ. IZA Discussion paper 930. 2003. Individual Mortality and Macroeconomic Conditions From Birth to Death.

Lumsdaine, Robin L.; Mitchell, Olivia. New developments in the economic analysis of retirement. In: Ashenfelter, OC.; Card, D., editors. Handbook of Labor Economics. 3. Elsevier; Amsterdam: 1999.

MacBride A. Retirement as a life crisis: myth or reality? Canadian Psychiatric Association Journal. 1976; 72:547-556. [PubMed: 799537]

Minkler M. Research on the health effects of retirement: an uncertain legacy. Journal of Health and Social Behavior. 1981; 22 (2):117-130. [PubMed: 7240711]

Natali, D. The Pension System Observatoire Social Européen Research Project: LA METHODE OUVERTE DE COORDINATION (MOC) EN MATIERE DES PENSIONS ET DE L'INTEGRATION EUROPEENNE. Service Public Fédéral Sécurité Sociale; 2004.

Neuman K. Quit your job and live longer? The effect of retirement on health. Journal of Labor Research. 2008; 29 (2):177-201.

Niemi T. Retirement and mortality. Scandinavian Journal of Social Medicine. 1980; 8:39-41. [PubMed: 7375877]

OECD. Economic Survey of Austria. 2003. http://www.oecd.org/dataoecd/5/16/27424371.pdf

OECD. Vieillissement et politiques de l'emploi. Ageing and Employment Policies; France: 2005. http://www.oecd.org/dataoecd/52/58/34591763.pdf

Poterba, J.; Venti, S.; Wise, DA. The transition to personal accounts and increasing retirement wealth: macro and micro evidence. In: Wise, DA., editor. Perspectives on the Economics of Aging. University of Chicago Press; Chicago: 2004.

Price, M. The development of the Euro-D Scale. In: John, RM.; Copeland; Abou-Saleh, MT.; Blazer, DG., editors. Principles and Practice of Geriatric Psychiatry. 2. Wiley and Sons Ltd; 2002.

Preesman, L. Dutch to Abolish Civil Service Retirement Age. IPE International Publishers Ltd; Netherlands: 2006.

Raz, N. The aging brain structural changes and their implications for cognitive aging. In: Dixon, RA.; Backman, L.; Nilsson, NG., editors. New Frontier in Cognitive Aging. University Press; Oxford: 2004. p. 115-133.

Rohwedder S, Willis RJ. Mental retirement. Journal of Economic Perspectives. 2010; 24 (1):119-138. [PubMed: 20975927]

Rowland KF. Environmental events predicting death for the elderly. Psychological Bulletin. 1977; 84:349-372. [PubMed: 840964]

Samwick AA. New evidence on pensions, social security, and the timing of retirement. Journal of Public Economics. 1998; 70(November 2):207-236.

Sheppard, HL. Work and retirement. In: Binstock, RH.; Shanas, E., editors. Handbook of Aging and the Social Sciences. Van Nostrand R; New York: 1976. p. 286-306.

Stern Y. What is cognitive reserve? Theory and research application of the reserve concept. Journal of the International Neuropsychology Society. 2002; 8:448-460.

Sundén, A. Pension Research Council Working Paper 2004-16. 2004. The Future of Retirement in Sweden.

The Bartelsmann Foundation. International Reform Monitor, Country info. http:// www.reformmonitor.org/index.php3?mode=status

Thompson WE, Streib GF. Situational determinants: health and economic deprivation in retirement. Journal of Social Issues. 1958; 14 (2):18-24.

Van der Klaauw W. Estimating the effect of financial aid offers on college enrollment: a regressiondiscontinuity approach. International Economic Review. 2003; 43:1249-1287.

Zissimopoulos, J.; Maestas, N.; Karoly, LA. RAND Working Paper 528. 2007. The Effect of Retirement Incentives on Retirement Behavior: Evidence from the Self-Employed In the United States and England. 


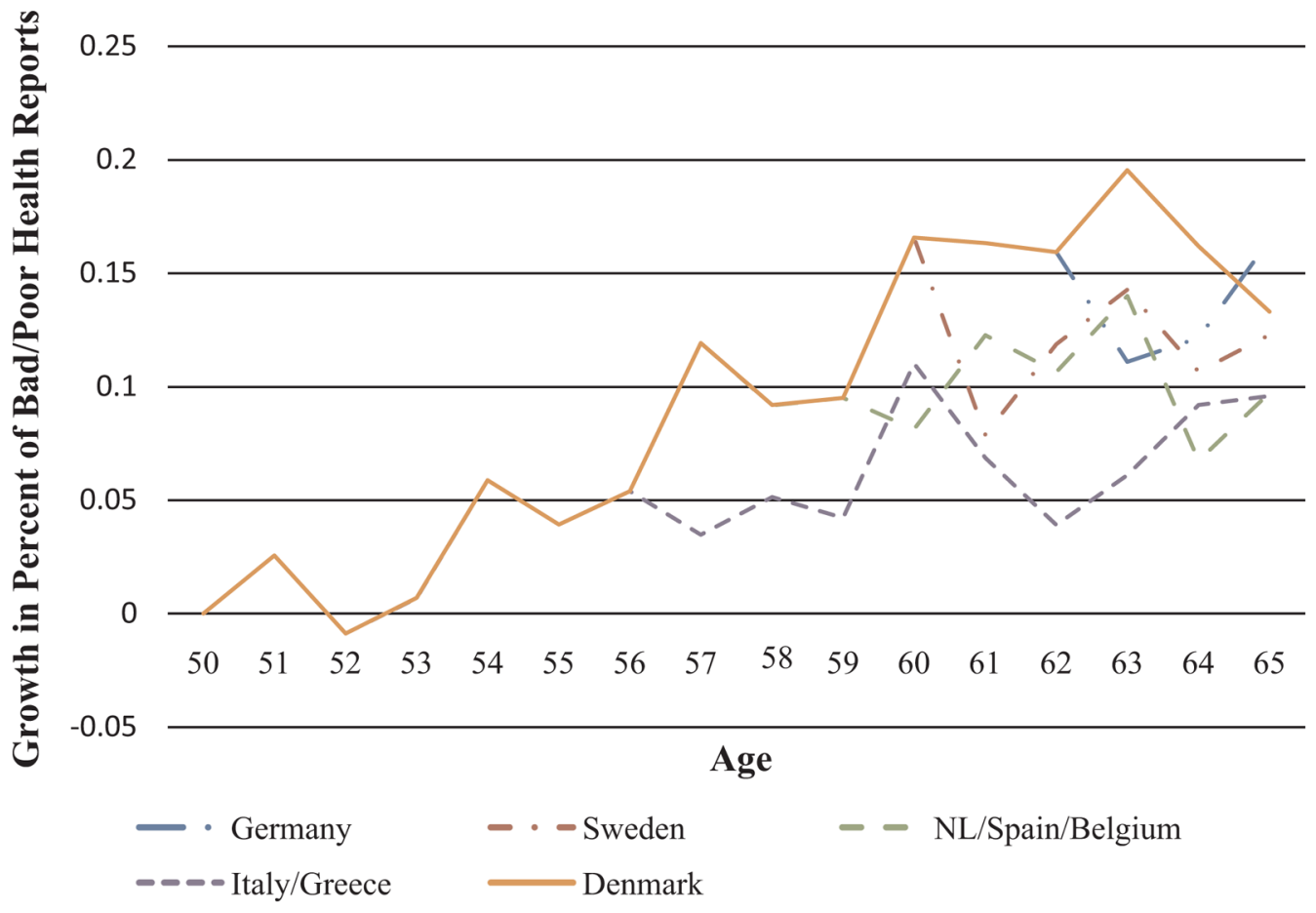

Fig. 1.

Age trends in fair/poor health, by early retirement age. 
Table 1

Pension age and retirement rates, by country.

\begin{tabular}{|c|c|c|c|c|}
\hline & \multirow[t]{2}{*}{ Retirement ages Early/normal } & \multicolumn{3}{|c|}{$\underline{\text { Retirement rates (percent) }}$} \\
\hline & & Under pension age & Over early retirement age & Over full retirement age \\
\hline Austria & $60 / 65$ & 20 & 86 & 97 \\
\hline Germany & $63 / 65$ & 28 & 69 & 91 \\
\hline Sweden & $61 / 65$ & 11 & 34 & 86 \\
\hline The Netherlands & $60 / 65$ & 10 & 69 & 97 \\
\hline Spain & $60 / 65$ & 13 & 60 & 93 \\
\hline Italy & $57 / 65$ & 11 & 65 & 89 \\
\hline France & $57 / 60$ & 11 & 49 & 95 \\
\hline Denmark & $-/ 65$ & 20 & - & 90 \\
\hline Greece & $57 / 65$ & 4 & 40 & 89 \\
\hline Switzerland & $63 / 65$ & 8 & 50 & 73 \\
\hline Belgium & $60 / 65$ & 26 & 77 & 98 \\
\hline
\end{tabular}




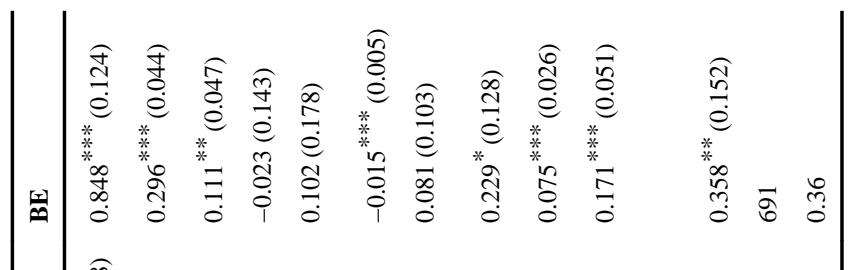

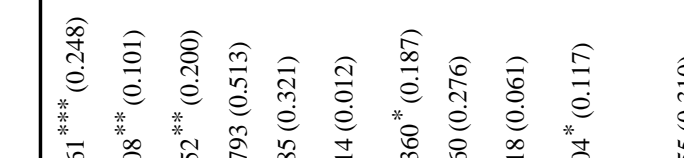

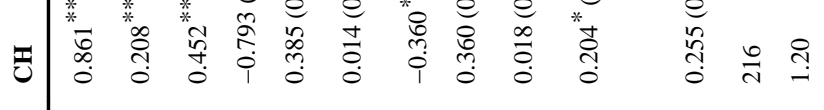

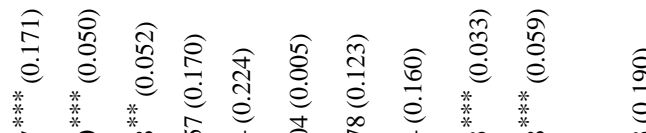
苟

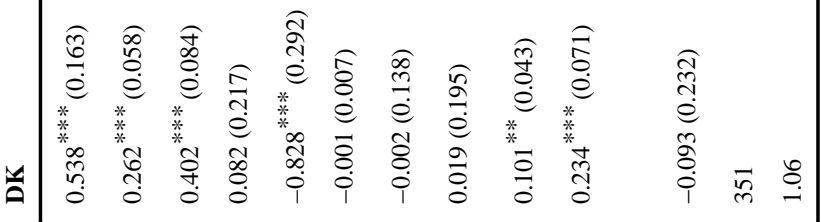

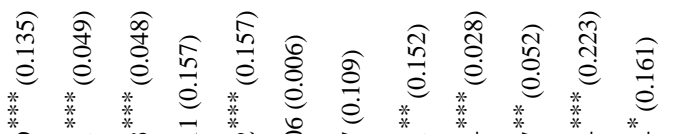

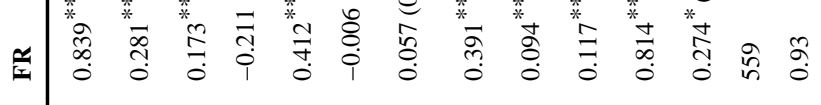

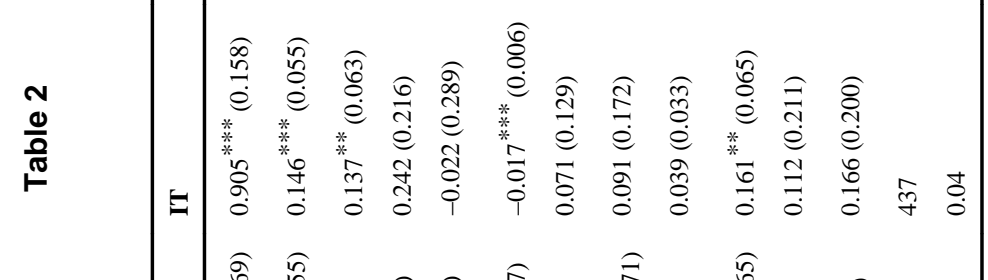

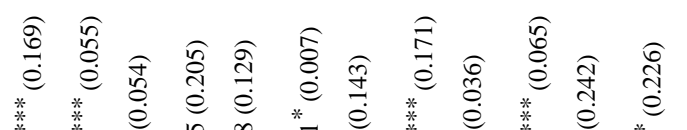

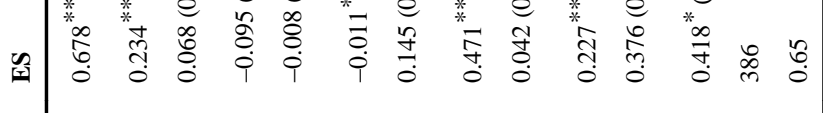

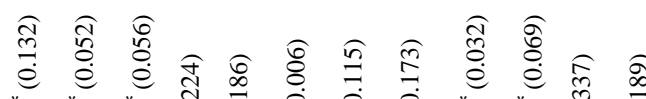

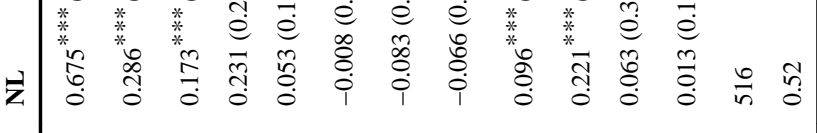

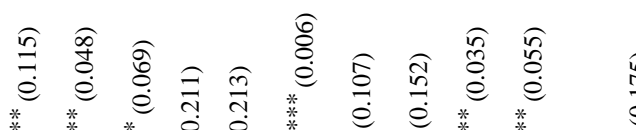

田

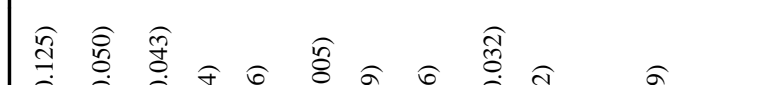

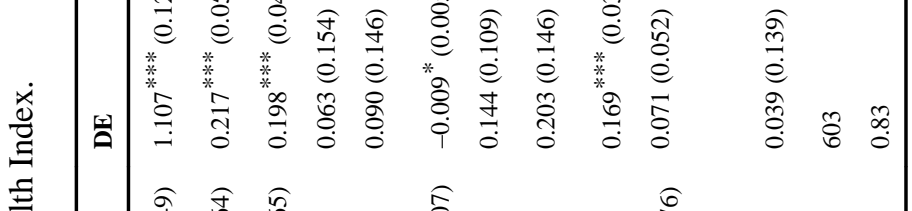

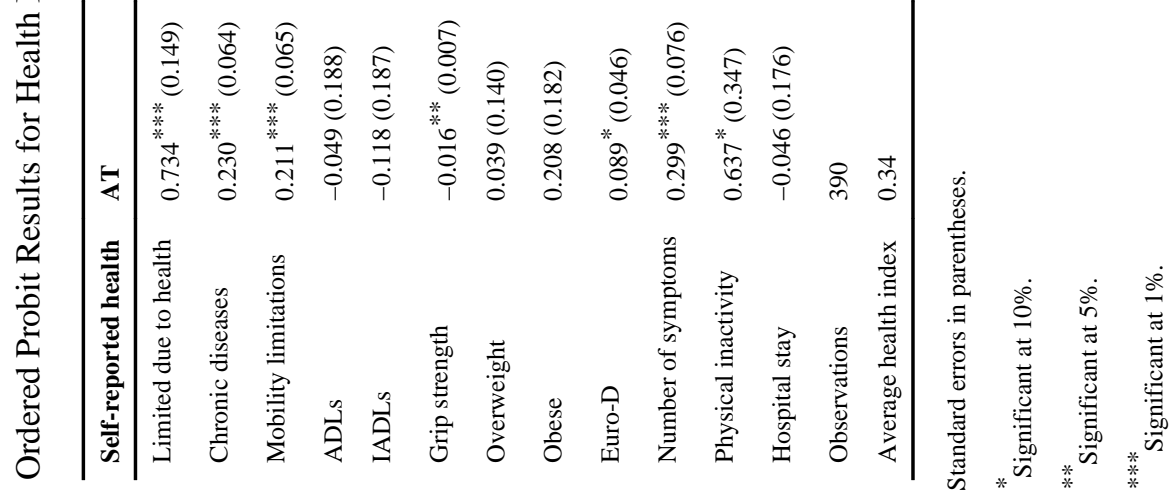


Table 3

Descriptive Statistics.

\begin{tabular}{|c|c|}
\hline & Average \\
\hline \multicolumn{2}{|l|}{ Demographics } \\
\hline Age (50-69) & 59 \\
\hline Over full retirement age & 0.24 \\
\hline Over early retirement age & 0.46 \\
\hline High education & 0.27 \\
\hline Medium education & 0.36 \\
\hline Married/co-resident & 0.81 \\
\hline \multicolumn{2}{|l|}{ Health measures } \\
\hline Fair/bad/very bad health & 0.25 \\
\hline Felt depressed in last month & 0.26 \\
\hline Euro-D Depression Scale (0-12) & 1.57 \\
\hline Maximum grip strength $(0-100)$ & 46.91 \\
\hline Limited due to health & 0.28 \\
\hline Number of chronic conditions $(0-8)$ & 1.16 \\
\hline Number of symptoms in last 6 months (0-9) & 0.97 \\
\hline Number of mobility limitations $(0-10)$ & 0.62 \\
\hline Number of ADL limitations (0-6) & 0.06 \\
\hline Number of IADL limitations (0-7) & 0.07 \\
\hline Hospital stay in previous year & 0.10 \\
\hline Overweight & 0.51 \\
\hline Obese & 0.17 \\
\hline \multicolumn{2}{|l|}{ Memory measures } \\
\hline Verbal score $(0-72)$ & 21.80 \\
\hline Memory recall (0-20) & 9.45 \\
\hline \multicolumn{2}{|l|}{ Employment } \\
\hline Retired & 0.45 \\
\hline Self-employed & 0.18 \\
\hline Public-sector employment & 0.12 \\
\hline \multicolumn{2}{|l|}{ Country representation } \\
\hline Austria & 0.07 \\
\hline Germany & 0.11 \\
\hline Sweden & 0.11 \\
\hline The Netherlands & 0.10 \\
\hline Spain & 0.07 \\
\hline Italy & 0.08 \\
\hline France & 0.11 \\
\hline Denmark & 0.07 \\
\hline Greece & 0.10 \\
\hline Switzerland & 0.04 \\
\hline
\end{tabular}




\begin{tabular}{lc}
\hline & Average \\
\hline Belgium & 0.13 \\
\hline
\end{tabular}


Table 4

First stage results.

\begin{tabular}{ll}
\hline Out of the labor force & OLS \\
\hline Over early retirement age & $0.0814^{* * *}(0.0231)$ \\
Over full retirement age & $0.1462^{* * *}(0.0180)$ \\
Age & $0.0399(0.0256)$ \\
Age squared & $0.0000(0.0002)$ \\
Public employment & $-0.0615^{* * *}(0.0151)$ \\
Self-employed & $-0.2017^{* * *}(0.0130)$ \\
Married & $-0.0090(0.0129)$ \\
High education & $-0.0976^{* * *}(0.0129)$ \\
Medium education & $-0.0213^{*}(0.0122)$ \\
Number of children & $-0.0027(0.0037)$ \\
Household income & $-0.3909(0.2517)$ \\
Constant & $-1.8946^{* * *}(0.7338)$ \\
Observations & 5282 \\
$R$-squared & 0.52 \\
\hline
\end{tabular}

Note: This regression also includes country fixed effects. Standard errors in parentheses.

Significant at $10 \%$.

*** Significant at $1 \%$. 
Table 6

Results: cognitive function.

\begin{tabular}{|c|c|c|c|c|}
\hline & \multicolumn{2}{|l|}{ Memory } & \multicolumn{2}{|l|}{ Verbal } \\
\hline & OLS & IV & OLS & IV \\
\hline Retired & $-0.2769^{* *}(0.1153)$ & $-0.0390(0.9798)$ & $-0.7544^{* * *}(0.2628)$ & $2.5647(2.2682)$ \\
\hline Age & $0.0132(0.1631)$ & $0.0203(0.1658)$ & $-0.0973(0.3718)$ & $0.0019(0.3837)$ \\
\hline Age squared & $-0.0007(0.0014)$ & $-0.0009(0.0015)$ & $0.0002(0.0031)$ & $-0.0023(0.0036)$ \\
\hline Public employment & $-0.3441^{* * *}(0.1259)$ & $-0.3298^{* *}(0.1389)$ & $-0.4915^{*}(0.2869)$ & $-0.2916(0.3216)$ \\
\hline Self-employed & $0.0241(0.1100)$ & $0.0705(0.2192)$ & $-0.1769(0.2506)$ & $0.4699(0.5074)$ \\
\hline Married & $0.1545(0.1032)$ & $0.1566(0.1036)$ & $0.5856^{* *}(0.2352)$ & $0.6142^{* *}(0.2398)$ \\
\hline High education & $1.7646^{* * *}(0.1095)$ & $1.7874^{* * *}(0.1438)$ & $3.5650 * * *(0.2496)$ & $3.8827^{* * *}(0.3329)$ \\
\hline Medium education & $1.0012^{* * *}(0.1014)$ & $1.0046^{* * *}(0.1024)$ & $1.5804^{* * *}(0.2312)$ & $1.6268^{* * *}(0.2370)$ \\
\hline Household income & $2.8554(2.0524)$ & $2.9376(2.0806)$ & $4.0035(4.6775)$ & $5.1506(4.8163)$ \\
\hline Foreign-born & $-0.6778^{* * *}(0.1540)$ & $-0.6843^{* * *}(0.1563)$ & $-2.5971^{* * *}(0.3509)$ & $-2.6877^{* * *}(0.3618)$ \\
\hline Number of chronic diseases & $0.0159(0.0372)$ & $0.0126(0.0396)$ & $0.0948(0.0848)$ & $0.0483(0.0917)$ \\
\hline Number of ADLs & $-0.1442(0.1445)$ & $-0.1465(0.1448)$ & $-0.0400(0.3293)$ & $-0.0714(0.3353)$ \\
\hline Number of IADLs & $-0.4177^{* * *}(0.1483)$ & $-0.4292^{* * *}(0.1555)$ & $-0.3921(0.3379)$ & $-0.5517(0.3600)$ \\
\hline Non-professional activities & $0.1779^{* * *}(0.0364)$ & $0.1759^{* * *}(0.0374)$ & $0.5911^{* * *}(0.0830)$ & $0.5627^{* * *}(0.0865)$ \\
\hline physically demanding activities & $0.1825^{* *}(0.0882)$ & $0.1968 *(0.1058)$ & $0.7988^{* * *}(0.2011)$ & $0.9977^{* * *}(0.2449)$ \\
\hline Moderate activities & $0.0060(0.1399)$ & $-0.0005(0.1425)$ & $1.1110^{* * *}(0.3189)$ & $1.0204^{* * *}(0.3298)$ \\
\hline $\begin{array}{l}\text { Hansen's J test } \\
P \text {-value }\end{array}$ & & $0.6084(0.4354)$ & & $1.5108(0.2190)$ \\
\hline Observations & 4928 & 4928 & 4928 & 4928 \\
\hline$R$-squared & 0.19 & 0.19 & 0.25 & 0.23 \\
\hline
\end{tabular}

Note: All regressions also include country dummy variables. Standard errors in parentheses.

Significant at $10 \%$.

** Significant at $5 \%$.

*** Significant at $1 \%$. 
Table 7

Age gradient of the retirement effect.

\begin{tabular}{llllll}
\hline & \multicolumn{1}{c}{ Bad health } & & Health index & \\
& OLS & IV & OLS & IV \\
\hline Retired $57-59$ & $0.1538^{* * *}(0.0174)$ & $-0.2505(0.2468)$ & $0.3832^{* * *}(0.0415)$ & $-0.6540(0.6087)$ \\
Retired 60-64 & $0.0636^{* * *}(0.0219)$ & $-0.5415^{* *}(0.2060)$ & $0.1737^{* * *}(0.0524)$ & $-1.5132^{* * *}(0.5081)$ \\
Retired 65-69 & $0.0078(0.0382)$ & $-0.5671^{*}(0.3434)$ & $0.02512(0.0912)$ & $-2.2850^{* * *}(0.8469)$ \\
Observations & 5282 & 5282 & 5282 & 5282 \\
\hline
\end{tabular}

Note: All regressions also include age, age squared, sector employment, marital status, educational attainment, number of children, household income, and country dummy variables. Standard errors in parentheses.

Significant at $10 \%$.

*** Significant at $5 \%$.

**** Significant at $1 \%$. 